\title{
A Proposed Fuzzy based Framework for Calculating Success Metrics of Agile Software Projects
}

\author{
Assem H. Mohammed \\ Department of Computer and Information \\ Sciences, Institute of Statistical Studies and \\ Research, Cairo University, Egypt
}

\author{
Nagy Ramadan Darwish \\ Department of Computer and Information \\ Sciences, Institute of Statistical Studies and \\ Research, Cairo University, Egypt
}

\begin{abstract}
Agile development methodologies are considered the most important guarantor for the success of software development project as they depend on the best practices in the development process rather than on the theatrical concepts. But, because of the unclear and ambiguous indicators within agility evaluation, most metrics are described in a form of human-like language by linguistic terms which are described by ambiguity and multi-possibility, so that such metrics cannot be effectively handled the conventional evaluation approaches. However, fuzzy logic provides useful techniques for dealing with decisions in such environments which contain imprecise and vague values. Accordingly, using of fuzzy logic techniques will be a good choice. Thus, this paper proposes a framework for calculating Success Metrics (SM) of agile software projects based on fuzzy logic to address the ambiguity in agility assessment. The paper presents the details of the proposed framework and an illustrative example.
\end{abstract}

\section{Keywords}

Agile Software Development, Effort Estimation, Story Points, Fuzzy Logic, Success Metrics

\section{INTRODUCTION}

Agile Software Development (ASD) is a set of best practices for software development that are iterative, incremental, selforganizing and emergent [1]. In other words ASD is iterative approach to software delivery that builds software incrementally from the beginning of the software project, instead of trying to deliver it all at once near the end $[2,3]$. Agile approaches break the projects down into small user functionality called user stories, prioritizing them, and then deliver them continuously in short two week iterations.

According to the using of such best practices provided by agile the productivity of the software development team is going to be $2000 \%$ over water fall model [4]. The agile manifesto was firstly presented in 2001 included the twelve principles of agile. There are many agile approaches but all were built on the ideas provided in the agile manifesto. Examples of such approaches are extreme Programming, scrum and Feature Driven Development [5, 6, 7, 8, 9, 10,11].

The success of any agile software project depends on a set of success metrics like quality, scope, cost and timelines [12]. Each one of such success metrics is affected by a set of success factors (SF) [13]. For example according to [14] for any software project there exist 36 success factors. Table (1) includes examples of these factors.
Table 1. Examples of success factors

\begin{tabular}{|c|c|}
\hline Dimension & Examples of Success Factors \\
\hline Organizational & $\begin{array}{ll}- & \text { Management commitment. } \\
\text { - } & \text { Organizational environment. } \\
\text { - } & \text { Team environment. }\end{array}$ \\
\hline People & $\begin{array}{ll}\text { - } & \text { Team capability. } \\
\text { - } & \text { Customer involvement. }\end{array}$ \\
\hline Process & $\begin{array}{ll}\text { - } & \text { Software project process. } \\
\text { - } & \text { Project management process. }\end{array}$ \\
\hline Technical & $\begin{array}{l}\text { - Techniques of the agile software. } \\
\text { The strategy for delivering the } \\
\text { product. }\end{array}$ \\
\hline Project & $\begin{array}{ll}- & \text { The nature of the project. } \\
\text { - } & \text { The schedule of the project. } \\
\text { - } & \text { Project type. }\end{array}$ \\
\hline
\end{tabular}

The values of agile metrics are evaluated as a result of these factors interacts with each other during the development of the project software. Such agile metrics that used to help the stakeholders of agile project to measure the progress of achieving their goals during the project development process from each one point of view like in $[4,15,16]$ as follows:

1. Committed Stories vs. Actual Stories Completed - the ability of the team to understand and discover its capabilities. Such capabilities appear in the comparing and measurement of the number of stories committed to in the planning of the sprint with the identified stories as completed in the review of the sprint [4].

2. Technical Debt Management - the known issues and problems submitted at the sprint end, which usually are measured by the bugs' number. Also it may include other deliverables such as materials of training, documentation of the users and delivery media [16].

3. Velocity of the Team - the team's estimates consistency from one sprint to another. It is calculated by comparing the completed story points in the current sprint with story points completed in the previous one; aim for $+/-10$ percent [4].

4. Quality of the Delivered Product- Is the product that the team is building fulfill the customer needs? Does each sprint adds value to the product customer and become a releasable piece of the needed product? It's not necessarily that the required product ready to release but rather the work is in progress, designed to solicit customer suggestions. This can be measured by surveying the stakeholders and customers [15]. 
5. Team Heartiness- the major factor for a successful agile team. If team members aren't enthusiastic, no methodology or process will be useful. Measuring team enthusiasm can be done by observing during various sprint meetings or, simply by asking team members if each team member feels happy and how he motivated to feel happy [16].

6. Retrospective Process Improvement - the ability of agile team to revise its process of development to make it more efficient and enjoyable for the next coming sprint. This could be measured by count the number of retrospective items that identified, the number of the retrospective items the team committed to addressing and the number of the items resolved by the end of the sprint [16].

7. Communication - how well the team, agile stakeholders, product owner, and are customers conducting honest and open communications. Through observing and listening you could get indications about how well each one is communicating [16].

8. Team's Obligation to Scrum Rules and Engineering Practices - Although scrum doesn't suggest engineering practices - unlike XP-most companies express numerous of their own for their projects. They want to confirm that the scrum team follows the rules the company defines. This can be measured by counting the number of breakings that occur during each sprint [16].

9. Team's Understanding of the Scope and Goal of the Sprint - a measure of how well the Scrum team realizes and focuses on the sprint goal and stories. The goal is usually aligned with the customer value and is defined in the acceptance standards of the stories. It could be determined through day-to-day contact and interaction with the team and customer feedback [15].

The paper focuses on such previous nine metrics as examples that could be measured using the proposed framework. Because of the values given to such success factor are flexible, the accuracy of calculating success metrics is a big challenge. But, because of the unclear and ambiguous indicators within agility evaluation, most metrics are described in a form of human-like language by linguistic terms which are described by ambiguity and multi-possibility, so that such metrics cannot be effectively handled the conventional evaluation approaches.

Fuzzy set theory was initiated in 1965 by Zadeh [17]. Since then, many researches and applications in many fields have been achieved. Fuzzy logic is a computing approach based on "degrees of truth" rather than the traditional Boolean logic "true or false" on which the modern computer is based. It allow to us to provide the elements values in a human like language values (like high, low and moderate) with a high accuracy in the calculation process.

The rest of this paper is organized as follows: The second section introduces the related works. The proposed approach is presented in the third section. The fourth section shows the conclusion and future works.

\section{RELATED WORKS}

Many approaches had been presented to enhance the agile software development process using soft computing techniques specially, fuzzy logic. A fuzzy logic based software cost estimation Model was introduced by Ziauddin A., et al to improve the effort estimation accuracy. The model fuzzifies the inputs parameters of COCOMO II model using Triangular fuzzy numbers are used to represent the linguistic terms. Finally, the model defuzzifies the result to be in normal natural numbers [18].

Vishal S., et al presented an optimized fuzzy logic based framework for effort estimation in software development. The performance of the proposed framework is established in terms of experimental validation carried on live project data of the COCOMO public database [19].

Abeer H. proposed a fuzzy based model for improving the sensitivity of COCOMO cost model. The proposed model improved the sensitivity and accuracy of COCOMO 81 intermediate model based on fuzzifying the cost drivers. The final results showed that the sensitivity of the proposed fuzzy based model is superior to COCOMO81 intermediate [20].

Sonia et al presented a fuzzy Logic Approach for Threat Prioritization in Agile Security Framework using DREAD (D: Damage, R: Reproducibility, E: Exploitability, A : Affected users and D: Discoverability) Model they propose a novel fuzzy based approach using DREAD model for evaluating the risk level that ensures better evaluation of imprecise concepts. Thus it provides the capacity to embrace subjectivity and vagueness during risk rank [21].

Tatiana et al presented a fuzzy logic model for evaluation of lean and agile manufacturing integration .The research model is based on the parameters of the agile manufacturing and the waste sources related to the lean production. The essential mixture of the model origins will be determined with help of fuzzy logic. The formed generic model can be used for the different types of the companies including the metallurgy by changing the meaning of the examined coefficients and their weights [22].

Atef et.al presented a fuzzy based framework for effort estimation in agile software development. The main focus of this paper is the application of fuzzy logic in improving the accuracy of effort estimation using the user stories by defining inputs parameters using trapezoidal fuzzy membership functions. In this paper, the researchers proposed a fuzzy based framework which receives fuzzy input values of Story Points, Implementation Level Factor, and Friction factors and Dynamic Forces to be handled in many successive steps to produce in final the effort estimation [23].

Tsun et al presented a survey study of critical success factors in agile software projects. This study uses survey data to explore the critical factors for success of agile software development projects using quantitative approaches. The data collected from 109 agile projects from a various group of organizations of various sizes, businesses, and geographic locations provided enough experimental information for statistical analysis to arrive at a number of conclusions [14].

Lin. et al presented a development of the absolute agility index, a unique and unprecedented attempt in agility measurement, based on fuzzy logic to address the vagueness in agility evaluation. The paper presented the Details of the approach and a framework of a fuzzy agility evaluation .Also, an illustrative example was also used to illustrate the approach developed [24].

\section{THE PROPOSED APPROACH}

The success of the agile software project is depend on a set of success metrics that used to measure the progress of the agile software project which by itself affected by a set of success factors. Unfortunately, the values of such success factors are 
unclear and ambiguous accordingly, the resulted metrics will be imprecise. Thus, the fuzzy based framework that showed in figure 1 proposes a new technique for calculating such success metrics from the success factor values which have been given in a human like language. The proposed fuzzy framework calculates the success metrics values as follows:

- Definition of success factors cards generator function.

- Generate success metrics fuzzy membership functions.
- Insert success factors values and priorities.

- Calculate the suitability membership value of each factor.

- $\quad$ Calculate the success metrics values.

A. Definition of success factors cards generator function To make it easy to determine the values that the stakeholders of the project give to each success factor, the agile expert defines success factors cards generator's function.

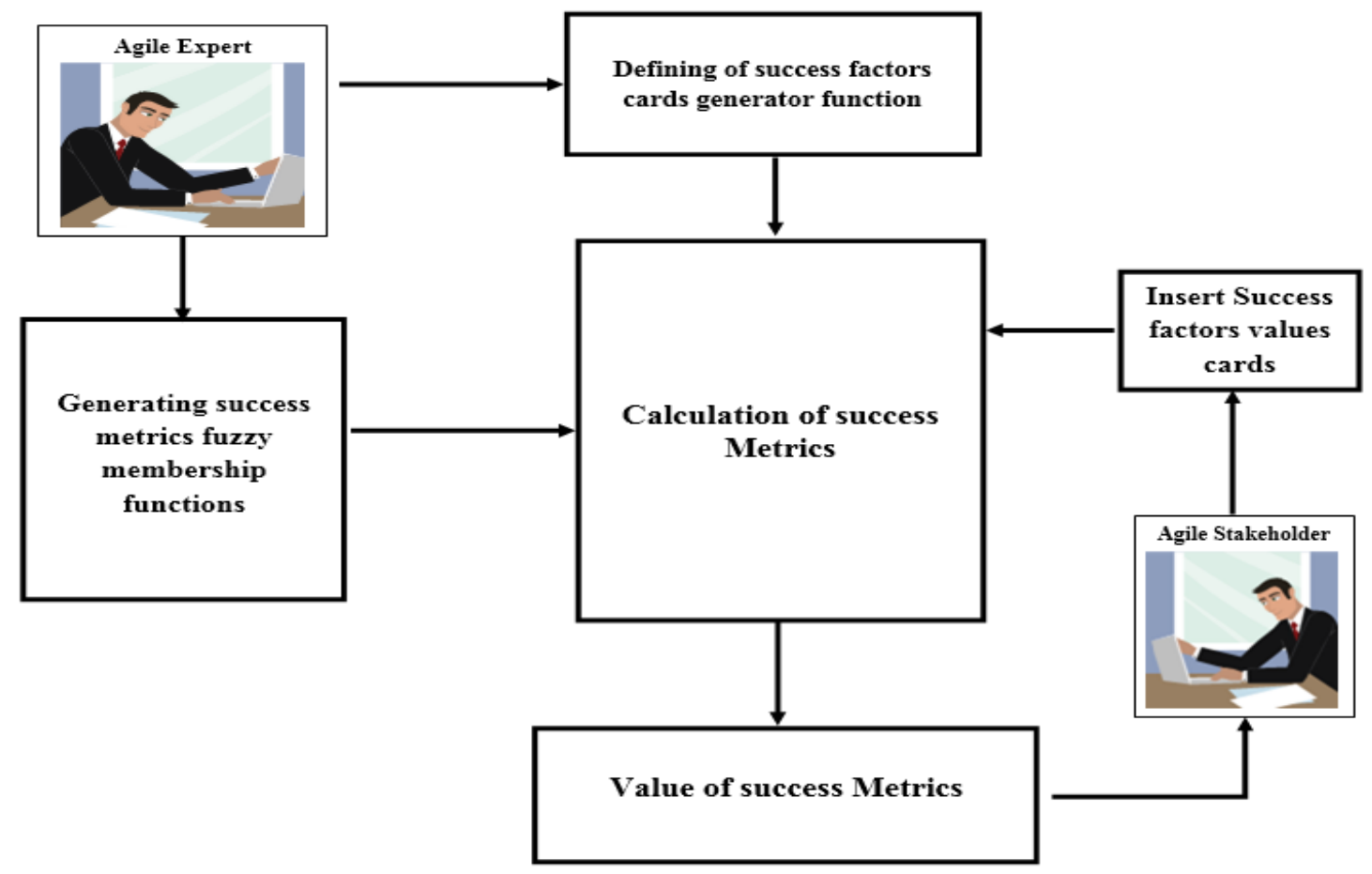

Fig 1: The proposed framework architecture

For example, for a specific factor if it takes values from 0 to 100 every set of values could be expressed by a colored card like in figure 2. The lavender card (C-) for values [50, 60[, blue-gray $(\mathrm{C})$ for values $[60,70[$ and light turquois $(\mathrm{C}+)$ for values [70,75[ .such colored cards are passed to the agile stakeholders to insert in when success metrics calculation process starts.

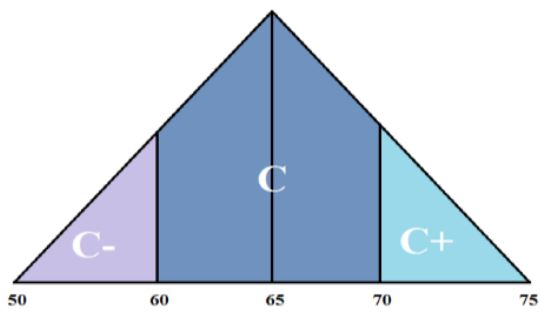

Fig 2: The agile cards color for a SF

B. Generate success metrics fuzzy membership functions At this step, the expert defines and generates the fuzzy membership functions. Such functions used to determine the membership value of each success factor in each success metrics value.
C. Insert success factors values and priorities

In this step, the agile stakeholder inserts the value and the priority of each success factor in a specific success metrics. The value of each success factor is in linguistic form like $\mathrm{C}+$, $\mathrm{C}, \mathrm{C}-$, etc.

D. Calculate the suitability membership value of each factor The acceptance fuzzy membership of the success metric is defined according to the accepted value of such success metric. Figure 3 shows an example of acceptance fuzzy membership of a success metric and the acceptance fuzzy membership value of each success factor of such success metric is calculated according to the equation (1).

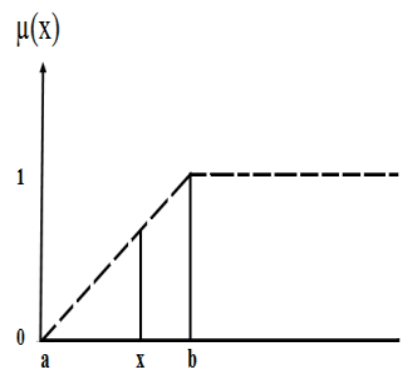

Fig 3: Fuzzy membership function for a SM 
$\mu_{\mathrm{SF}}(\mathrm{SM}, \mathrm{x})= \begin{cases}0 & \text { if } \mathrm{x}<a \\ \frac{\mathrm{x}-\mathrm{a}}{\mathrm{b}-\mathrm{a}} & \text { if } \mathrm{a} \leq \mathrm{x}<b \quad \text { EQ (1) } \\ 1 & \text { if } \mathrm{x} \geq \mathrm{b}\end{cases}$

Where $a=$ the min value, $b=$ the $\max$ value

For example the blue-gray $(\mathrm{C})$ values for specific success factor between $[60,70[$ and $a=50, b=90$

Low Success factor membership value of the card C $=\frac{60-50}{90-50}=0.25$

High Success factor membership value of the card C $=\frac{70-50}{90-50}=0.50$

\section{E. Calculate the success metrics values}

In this module, the framework calculates the Success metric value (SMV) using the Success factors values (SFV) and the Importance value (IM) for each Success factor value (SF). The equation $(2,3)$ show how to calculate the (SMV) using (SFV) and (IM) suggested by one agile stakeholder as follows:

$\operatorname{Low}(S M V)=\sum_{i=1}^{n} \operatorname{low}(S F V)_{i} * I M_{i} \quad$ EQ (2)

Where $n=$ the number of success factors

$\operatorname{High}(S M V)=\sum_{i=1}^{n} \operatorname{High}(S F V)_{i} * I M_{i}$ EQ (3)

Where $n=$ the number of success factors

Finally, if there exist more than one agile stakeholder that will involve in the evaluation of SMV the final results will be calculated as in equation $(4,5)$ as follows:

final Low $(S M V)=\frac{\sum_{i=1}^{m} \operatorname{Low}(S M V)_{i}}{m}$

Where $m=$ the number of agile stakeholders

final High $(S M V)=\frac{\sum_{i=1}^{m} \operatorname{High}(S M V)_{i}}{m}$

Where $m=$ the number of agile stakeholders

\section{ILLUSTRATIVE CASE STUDY}

In this example, the researchers want to calculate the expected quality as a success metric of a software project according to the current values of the success factors that affect the quality success metric.

Firstly, According to [14] the quality success metric affected by a set of success factors that presented in table2, the first column shows the factor name and the second column shows the values of such success factors where every range of values is presented by a card. Such cards are generated by the cards generator functions that were defined by the agile experts.

Secondly, the agile stakeholders use the cards that were generated before to express the value that he expected for each success factor when success metric calculation process starts. Accordingly, the fuzzy membership values of such cards are calculated using the suitability fuzzy membership functions for the agile success metric that were defined by agile experts.
Table 2: the values of SF that affects quality metric

\begin{tabular}{|c|c|}
\hline Factor & Values \\
\hline $\begin{array}{l}\text { 1-Facility with proper } \\
\text { agile-style work } \\
\text { environment (factor1) }\end{array}$ & $\begin{array}{ll}- & \text { C- card :for values } \\
& \text { from } 50 \text { to } 60 \\
\text { - } & \text { C card: for values from } \\
& 60 \text { to } 70 \\
\text { - } & \text { C+ card: for values } \\
\text { from } 70 \text { to } 75\end{array}$ \\
\hline $\begin{array}{l}\text { 2-Following agile- } \\
\text { oriented project } \\
\text { management process } \\
\text { (factor2) }\end{array}$ & $\begin{array}{ll} & \text { C- card :for values } \\
& \text { from } 50 \text { to } 60 \\
\text { - } & \text { C card: for values from } \\
& 60 \text { to } 70 \\
\text { - } & \text { C+ card: for values } \\
& \text { from } 70 \text { to } 75 \\
\end{array}$ \\
\hline $\begin{array}{l}\text { 3- Agile software } \\
\text { engineering techniques } \\
\text { (factor3) }\end{array}$ & $\begin{array}{ll}\text { - } & \text { C- card :for values } \\
& \text { from } 50 \text { to } 60 \\
\text { - } & \text { C card: for values from } \\
& 60 \text { to } 70 \\
\text { - } & \text { C+ card: for values } \\
& \text { from } 70 \text { to } 75\end{array}$ \\
\hline
\end{tabular}

In this case study, the researchers assume that the three success factors have the same range for all divided sets and that for the evaluation of factor1 the agile stakeholder agrees that its value is $\mathrm{C}$ (blue-gray Card) with importance value .3, factor2 its value is $\mathrm{C}+$ (light turquois Card) with importance value 0.6 and for factor 3 its value is $\mathrm{C}$ - (lavender Card) with importance value 0.1 . if it is assumed that the suitability fuzzy membership function in figure 3 and equation(1) is the suitability fuzzy membership function for quality success metric, The low fuzzy membership value (LFMV) and high fuzzy membership value (HFMV) of each success factors will be calculated as follows:

$$
\begin{aligned}
& \text { LFMV of factor } 1=\frac{60-50}{90-50}=0.25 \\
& \text { HFMV of factor } 1=\frac{70-50}{90-50}=0.50 \\
& \text { LFMV of factor } 2=\frac{70-50}{90-50}=0.50 \\
& \text { HFMV of factor } 2=\frac{75-50}{90-50}=0.625 \\
& \text { LFMV of factor } 3=\frac{50-50}{90-50}=0.0 \\
& \text { HFMV of factor } 3=\frac{60-50}{90-50}=0.25
\end{aligned}
$$

Table3 and figure 4 summarize the high and low fuzzy membership values (FMVs) of each success factors that affect quality metric and the importance of each factor.

Table 3: Summary of FMVs of SF that affects quality

\begin{tabular}{|l|l|l|l|}
\hline $\begin{array}{l}\text { Success } \\
\text { factor }\end{array}$ & LFMV & HFMV & $\begin{array}{l}\text { Importance } \\
\text { value (IM) }\end{array}$ \\
\hline Factor1 & 0.25 & 0.50 & 0.3 \\
\hline Factor2 & 0.50 & 0.625 & 0.6 \\
\hline Factor3 & 0 & 0.25 & 0.1 \\
\hline
\end{tabular}




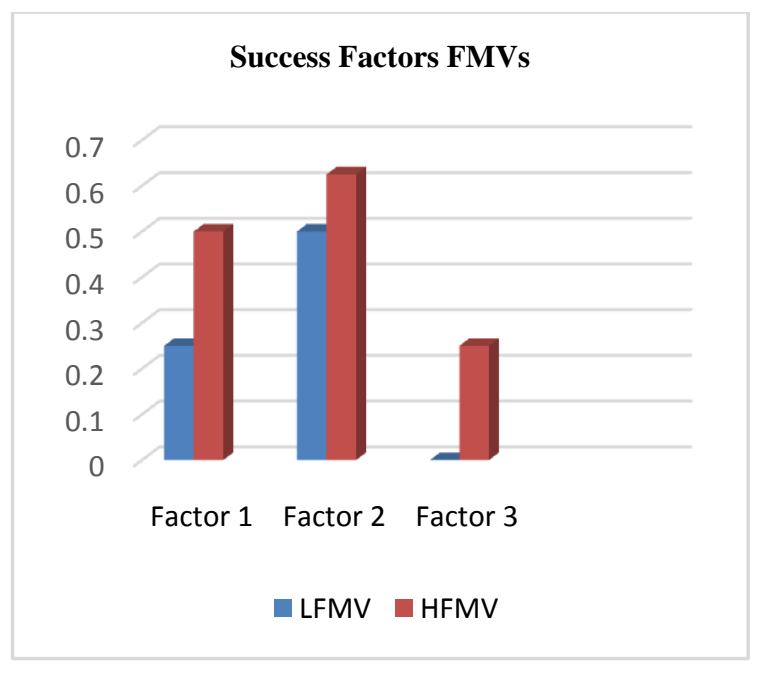

Fig4: FMVs of SF that affects quality

Finally, the success metric (quality) values are calculated as follows:

High value of quality success metric $=(\mathrm{HMV}$ of factor $1 * \mathrm{IM}$ of factor 1$)+(\mathrm{HMV}$ of factor $2 *$ IM of factor 2$)+(\mathrm{HMV}$ of factor $3 *$ IM of factor3)

High value of quality success metric $=(0.50 * 0.3)+$ $(0.625 * 0.6)+(0.25 * 0.1)=0.55=55 \%$

Low value of quality success metric $=($ LMV of factor $1 *$ IM of factor 1$)+(\mathrm{LMV}$ of factor2* IM of factor2) + (LMV of factor $3 *$ IM of factor 3 )

Low value of quality success metric $=(0.25 * 0.3)+(0.50 * 0.6)$ $+(0.0 * 0.1)=0.375=37.5 \%$

In the previous example, the scenario for only one agile stakeholder is applied if there exist more than one agile stakeholder involved in the evaluation process the results will be the summation of high value of quality success metric for the point of view of each agile stakeholder divided by the number of all agile stakeholders and the final value will be calculated as in equation $(4,5)$.

According to the results from the case study the proposed fuzzy based framework allow to agile stakeholders to represent the values of the success factors in a human-like language which is more flexible to agile concepts. But at the same time the framework uses such values and provides the success metrics value in a numeric form.

\section{CONCLUSION}

This paper presents a fuzzy based framework for calculating success metrics for agile development process. The framework gives the agile stakeholders the ability to evaluate the success factors values in human-like language which is more flexible to agile concepts. At the same time, the framework gives a technique to calculate the more accurate value of the success metrics.

As a future work, the researchers plan to make the framework more generic handle all agile metrics and to test the proposed framework results in wide range of agile software projects.

\section{REFERENCES}

[1] Cohen, David, Mikael Lindvall, and Patricia Costa. 2004. an introduction to agile methods", Advances in computers 62, pp. 1-66.
[2] http://www.slideshare.net/pravinasar/agilemethodologies-inprojectmanagement [accessed date 120-2015].

[3] http://www.slideshare.net/HDmedia/learn-agile-scrumdevelopment-for-project-managers [accessed date 1-202015].

[4] Downey, S., \& Sutherland, J. 2013. Scrum metrics for hyperproductive teams: how they fly like fighter aircraft. In System Sciences (HICSS), 2013 46th Hawaii International Conference on (pp. 4870-4878). IEEE.

[5] Fruhling, A. L., \& Tarrell, A. E. 2008. Best Practices for Implementing Agile Methods. IBM center for the Business government.

[6] Cohen, D., Lindvall, M., \& Costa, P. 2004. An introduction to agile methods. Advances in computers, 62, 1-66.

[7] Panagiotis Sfetsos, P. S., \& Sfetsos, P. 2007. Agile Software Development Quality Assurance. Idea Group, ISBN 978-1-59904-216-9, 2007.

[8] John, Hunt. 2006. Agile software construction. Springer. ISBN-10: 1-85233-944-6.

[9] Vlaanderen, K., Jansen, S., Brinkkemper, S., \& Jaspers, E. 2011. The agile requirements refinery: Applying SCRUM principles to software product management. Information and software technology, 53(1), 58-70.

[10] Cohn, M. 2010. Succeeding with agile: software development using Scrum. Pearson Education.

[11] Abrahamsson, P., Salo, O., Ronkainen, J., \& Warsta, J. 2002. Agile software development methods: Review and analysis. VTT, ISBN 951-38-6009-4

[12] http://softwarealliancewales.com/6-top-success-factorsagile-software-projects [accessed date 1-22-2015].

[13] Taherdoost, Hamed, and Abolfazl Keshavarzsaleh. 2015. A Theoretical Review on IT Project Success/Failure Factors and Evaluating the Associated Risks. Proceedings of 14th International Conference on Telecommunications and Informatics, At Sliema, Malta.

[14] Chow, Tsun, and Dac-Buu Cao. 2008. A survey study of critical success factors in agile software projects. Journal of Systems and Software 81.6, 961-971.

[15] Hayes W., Miller S., Lapham M. A., Wrubel E. and Chick T. 2014. Agile Metrics: Progress Monitoring of Agile Contractors. No. Cmu/sei-2013-tn-029. Carnegiemellon univ pittsburgh pa software engineering inst.

[16] http://pragmaticmarketing.com/resources/9-scrummetrics-to-keep-your-team-on-track[accessed date 1-202015].

[17] Zadeh, L. A. 1978. Fuzzy sets as a basis for a theory of possibility. Fuzzy sets and systems, 1(1), 3-28.

[18] Ziauddin, Shahid Kamal, Shafiullah khan and Jamal Abdul Nasir. 2013. A Fuzzy Logic Based Software Cost Estimation Model. International Journal of Software Engineering and Its Applications (IJSEIA). Vol. 7. Issue 2. 2013.

[19] Sharma, V., \& Verma, H. K. 2010. Optimized fuzzy logic based framework for effort estimation in software development. arXiv preprint arXiv:1004.3270. 
[20] Hamdy, A. 2012. Fuzzy Logic for Enhancing the Sensitivity of COCOMO Cost Model. Journal of Emerging Trends in Computing and Information Sciences, 3(9), 1292-1297.

[21] Singhal, A., \& Banati, H. 2013. Fuzzy Logic Approach for Threat Prioritization in Agile Security Framework using DREAD model. arXiv preprint arXiv:1312.6836.

[22] Ing. Tatiana USTYUGOVA, Ing. Darja NOSKIEVIÈOVÁ, CSc. 2013. Fuzzy logic model for evaluation of lean and agile manufacturing integration. proceedings of 22nd International Conference on Metallurgy and Materials , Brno, Czech Republic,EU.

[23] Raslan, A. T., Darwish, N. R., \& Hefny, H. A. 2015. Towards a Fuzzy based Framework for Effort Estimation in Agile Software Development. International Journal of Computer Science and Information Security, 13(1), 37. 